\title{
Decentralization and regional government size in Spain
}

\author{
David Cantarero $\cdot$ Patricio Perez
}

Received: 19 October 2011 / Accepted: 21 August 2012 / Published online: 19 September 2012 (C) Springer-Verlag 2012

\begin{abstract}
The aim of this paper is to investigate the impact of fiscal decentralization on the size of regional governments in Spain, by controlling for economies of scale, interregional heterogeneity and institutional framework. We study it over 1985 to 2004 using a panel dataset of seventeen spanish regions. The results can be easily summarized. Firstly, it supports the classic public goods theory of a trade-off-between the economic benefits of size and the costs of heterogeneity. Secondly, it doesn't reject the "Leviathan" hypothesis and neither does the "common pool" hypothesis. Thirdly, by contrast, the paper partly rejects the "Wallis" hypothesis. It argues that government size is mediated by financial resources obtained through intergovernmental grants, consistent with welfare economics and positive economic policies. We conclude that later advances in the decentralisation process must be compatible with the goal of reducing fiscal imbalances that emanate from the vertical structure of fiscal power.
\end{abstract}

Keywords Government size - Fiscal decentralization · "Leviathan" hypothesis · Vertical imbalances · Flypaper effect

JEL Classification $\mathrm{H} 72 \cdot \mathrm{H} 77 \cdot \mathrm{R} 5$

D. Cantarero ' P. Perez

Department of Economics, University of Cantabria, Avda. Los Castros, s/n, 39005 Santander, Spain

e-mail: david.cantarero@unican.es

P. Perez

e-mail: patricio.perez@unican.es 